\title{
Generation of Genetically Modified Mice Using the CRISPR-Cas9 Genome-Editing System
}

\author{
Jorge Henao-Mejia, 1,2,6,7 Adam Williams, ${ }^{3,6,7}$ Anthony Rongvaux, ${ }^{4}$ Judith Stein, 4,5 \\ Cynthia Hughes, ${ }^{4,5}$ and Richard A. Flavell $4,5,7$ \\ ${ }^{1}$ Institute for Immunology, Perelman School of Medicine, University of Pennsylvania, Philadelphia, Pennsylvania \\ 19104; ${ }^{2}$ Division of Transplant Immunology, Department of Pathology and Laboratory Medicine, Children's \\ Hospital of Philadelphia, University of Pennsylvania, Philadelphia, Pennsylvania 19104; ${ }^{3}$ The Jackson Laboratory \\ for Genomic Medicine, Department of Genetics and Genome Sciences, University of Connecticut Health Center, \\ Farmington, Connecticut 06032; ${ }^{4}$ Department of Immunobiology, Yale University School of Medicine, New \\ Haven, Connecticut 06520; ${ }^{5}$ Howard Hughes Medical Institute, Yale University School of Medicine, New Haven, \\ Connecticut 06520
}

Genetically modified mice are extremely valuable tools for studying gene function and human diseases. Although the generation of mice with specific genetic modifications through traditional methods using homologous recombination in embryonic stem cells has been invaluable in the last two decades, it is an extremely costly, time-consuming, and, in some cases, uncertain technology. The recently described CRISPR-Cas9 genome-editing technology significantly reduces the time and the cost that are required to generate genetically engineered mice, allowing scientists to test more precise and bold hypotheses in vivo. Using this revolutionary methodology we have generated more than 100 novel genetically engineered mouse strains. In the current protocol, we describe in detail the optimal conditions to generate mice carrying point mutations, chromosomal deletions, conditional alleles, fusion tags, or endogenous reporters.

MATERIALS

It is essential that you consult the appropriate Material Safety Data Sheets and your institution's Environmental Health and Safety Office for proper handling of equipment and hazardous materials used in these recipes.

RECIPES: Please see the end of this protocol for recipes indicated by $<R>$. Additional recipes can be found online at http://cshprotocols.cshlp.org/site/recipes.

\section{Reagents}

Agarose I (Molecular Biology Grade) (Life Technologies 17850)

Agilent RNA 6000 Pico Kit (Agilent Technologies 5067-1513)

Circular DNA donor vector plasmid (optional; see Step 2)

These vectors are used for performing large fragment insertions.

CutSmart buffer (New England Biolabs B7204S)

\footnotetext{
${ }^{6}$ These authors contributed equally to this work.

${ }^{7}$ Correspondence: jhena@mail.med.upenn.edu, adam.williams@jax.org, richard.flavell@yale.edu

(C) 2016 Cold Spring Harbor Laboratory Press

Cite this protocol as Cold Spring Harb Protoc; doi:10.1101/pdb.prot090704
} 
DNeasy Blood \& Tissue Kit (QIAGEN 69581)

EDTA (0.5 M, pH 8.0) (AmericanBio AB00502-01000)

EndoFree Plasmid Maxi Kit (QIAGEN)

Gene-specific primers for genotyping (Sigma-Aldrich)

Human chorionic gonadotropin (hCG; Sigma-Aldrich C8554)

Hyaluronidase (from bovine testes) (Sigma-Aldrich H4272)

M2 medium (Sigma-Aldrich M7167)

M16 medium (Sigma-Aldrich M7292)

MEGAclear Transcription Clean-Up Kit (Life Technologies AM1908)

MEGAshortscript T7 Transcription Kit (Life Technologies AM1354)

Mice, C57BL/6, age 3-4 wk (female) and $>8 \mathrm{wk}$ (male) (The Jackson Laboratory)

These mice are used to produce zygotes.

Mice, ICR (Institute for Cancer Research) (CD-1) mice (males and females) (Charles Rivers

Laboratories)

These are used for pseudopregnant foster mothers and vasectomized males.

Mineral oil, light (Sigma-Aldrich 330779)

mMESSAGE mMACHINE T7 Ultra Transcription Kit (Life Technologies AM1345)

Nuclease-free water (not DEPC [diethylpyrocarbonate]-treated) (Life Technologies AM9932)

Oligo DNAs used for in vitro transcription (Sigma-Aldrich)

sgRNA template: 5'-NNNNNNNNNNNNNNNNNNNNGTTTTAGAGCTAGAAATAGCAAGT

TAAAATAAGGCTAGTCCGTTATCAACTTGAAAAAGTGGCACCGAGTCGGTGCTTTTTT-3' sgRNA_R: 5'-AAAAAAGCACCGACTCGGTG-3'

T7-sgRNA_F: 5'-GAAATTAATACGACTCACTATAGGGAGANNNNNNNNNNNNNNNNNN

NNGTTTTAGA-3'

Phenol:chloroform:isoamyl alcohol 25:24:1 (saturated with 10 mM Tris, pH 8.0, 1 mm EDTA) (SigmaAldrich 2069)

Platinum Taq DNA Polymerase, High-Fidelity (Life Technologies 11304-011)

pMJ920 plasmid (Addgene 42234)

This plasmid contains the Cas9 coding region.

Pregnant mare serum gonadotropin (PMSG; Sigma-Aldrich G4527)

QIAquick PCR Purification Kit (QIAGEN 28106)

Single-strand DNA (ssDNA) (Integrated DNA Technologies) (see Step 2)

These oligo DNAs are used to insert small DNA fragments and should be ordered as a 4-nm ultramer, desalted. Include phosphorothioate linkages to prevent degradation in the first and last three nucleotides of the oligo DNAs.

Sodium dodecyl sulfate (SDS) $(20 \%)<\mathrm{R}>$

ssDNA/RNA Clean and Concentrator kit (Zymo Research D7010)

SURVEYOR Mutation Detection Kit - S100 (Integrated DNA Technologies 706020) (optional; see

Steps 59-64)

TOPO TA Cloning Kit for subcloning (Invitrogen 450641) (optional; see Steps 59-64)

Tris (1 M, pH 7.0) (Life Technologies AM9850G)

Tris (1 M, pH 8.0) (Life Technologies AM9855G)

Tris-acetate-EDTA (TAE) buffer $<$ R $>$

Tsg DNA polymerase (Lambda Biotech D101-200) (optional; see Steps 59-64)

XbaI (New England BioLabs R0145S)

Equipment

2100 Bioanalyzer (Agilent Technologies G2940CA)

C1000 Touch Thermal Cycler (Bio-Rad) 
J. Henao-Mejia et al.

$\mathrm{CO}_{2}$ incubator (Thermo Scientific BB15)

Femtotip injection capillaries, sterile (Eppendorf 930000035)

IX73 Inverted microscope, with Hoffman optics (Olympus IX73)

Microcentrifuge (Eppendorf 5424)

Microcentrifuge, refrigerated (Eppendorf 5424R)

Microinjector, CellTram vario (Eppendorf 5176000084)

Micromanipulator, three-axis hanging joystick, oil hydraulic (Narishige MMO-202ND)

Micropipettes, small holding, $20^{\circ}$ angled (Origio MPH-SM-20)

Needles, 26 G × $3 / 8$ in. (Becton Dickinson 309625)

Stereomicroscope (Olympus SZX7)

Tissue culture dishes, BD Falcon, polystyrene, sterile $(60 \times 15 \mathrm{~mm})$ (Becton Dickinson 351007$)$

These dishes are used for embryo culture.

Tissue culture dishes, BD Falcon, polystyrene, sterile $(100 \times 20 \mathrm{~mm})$ (Becton Dickinson 353003$)$

Bottoms are suitable for oocyte/embryo collection; lids are suitable for micromanipulation.

Transfer pipette capillaries, glass, thin-wall, 6 in., $1 \mathrm{~mm}$ o.d., $0.75 \mathrm{~mm}$ i.d. (WPI TW100F-6)

\section{METHOD}

\section{Single Guide RNA (sgRNA) Design}

1. For sgRNA design, follow the protocol described by Ran et al. (2013).

The type of sgRNA required will depend on the specific type of genetic alteration desired.

- For gene knockouts by indels, design the sgRNA for the targeted gene. For multiple-gene knockouts by indels in a single embryo, design two or more sgRNAs to target each gene.

- For targeted chromosomal deletions, design two sgRNAs, each of which will generate a double-strand break (DSB) at the start and end point of the sequence to be deleted.

- To introduce a small DNA sequence (e.g., point mutation, fusion tag), design a single sgRNA.

- To generate a conditional allele by inserting two loxPs in cis, design two sgRNAs at the insertion sites of interest.

- To introduce a large DNA sequence (e.g., a fluorescent protein) by homologous recombination (HR), design a single sgRNA at the insertion site of interest.

\section{Donor Design}

2. Design donor DNA depending on the specific type of genetic alteration desired.

- To introduce a short DNA sequence (e.g., point mutation, fusion tag), design a singlestranded DNA (ssDNA) oligonucleotide that encodes the desired DNA insertion flanked on each side by 50-70 bases homologous to the sequence surrounding the sgRNA-mediated DSB. Insert the sequence as close as possible to the generated DSB.

We have been able to introduce up to 100 bases with homologous regions of 50 bases on each side.

- To generate a conditional allele by introducing two loxP sites, design two ssDNA oligonucleotides that encode the loxP sequence flanked on each side by 63 bases homologous to the sequence surrounding the sgRNA-mediated DSB. Insert the loxP sequence as close as possible to the generated DSB.

- To introduce a large DNA sequence (e.g., a fluorescent protein), design and construct a plasmid that encodes the DNA sequence to be inserted flanked by $>2 \mathrm{~kb}$ of homology on 
In Vitro Transcription and Purification of Cas9 mRNA

3. Linearize the pMJ920-Cas9 plasmid containing the Cas9 endonuclease coding region under the $\mathrm{T} 7$ promoter with $\mathrm{XbaI}$ by incubating the following reaction for $16 \mathrm{~h}$ at $37^{\circ} \mathrm{C}$.

Reagent Volume

Circular pMJ920-Cas9 plasmid

$\mathrm{XbaI}$ restriction enzyme

CutSmart buffer (10x)

Nuclease-free water

$$
\begin{aligned}
& 5 \mu \mathrm{L}(5 \mu \mathrm{g} \text { of plasmid total }) \\
& 0.5 \mu \mathrm{L} \\
& 5 \mu \mathrm{L} \\
& 39.5 \mu \mathrm{L}
\end{aligned}
$$

4. Add $1.5 \mu \mathrm{L}$ of proteinase $\mathrm{K}(150 \mathrm{ng} / \mu \mathrm{L})$ and $2.5 \mu \mathrm{L} 20 \%$ SDS to the reaction mix. Incubate for $30 \mathrm{~min}$ at $50^{\circ} \mathrm{C}$.

5. Analyze $5 \mu \mathrm{L}$ of the digestion reaction on a $1 \%(\mathrm{w} / \mathrm{v})$ agarose gel in TAE buffer to verify the successful linearization of the pMJ920-Cas9 plasmid.

6. Purify the linearized pMJ920-Cas9 plasmid with phenol:chloroform:isoamyl alcohol (25:24:1) according to the manufacturer's instructions. Resuspend the purified linearized pMJ920-Cas9 plasmid to a concentration of $1 \mu \mathrm{g} / \mu \mathrm{L}$ using nuclease-free water.

7. Use $1 \mu \mathrm{g}$ of the purified linearized pMJ920-Cas9 plasmid as the template for in vitro transcription to generate Cas9 mRNA using the mMESSAGE mMACHINE T7 Ultra Transcription Kit according to the manufacturer's instructions.

8. Purify the Cas9 mRNA using the MEGAclear Transcription Clean-Up Kit according to the manufacturer's instructions, and elute it with $65 \mu \mathrm{L}$ of elution buffer.
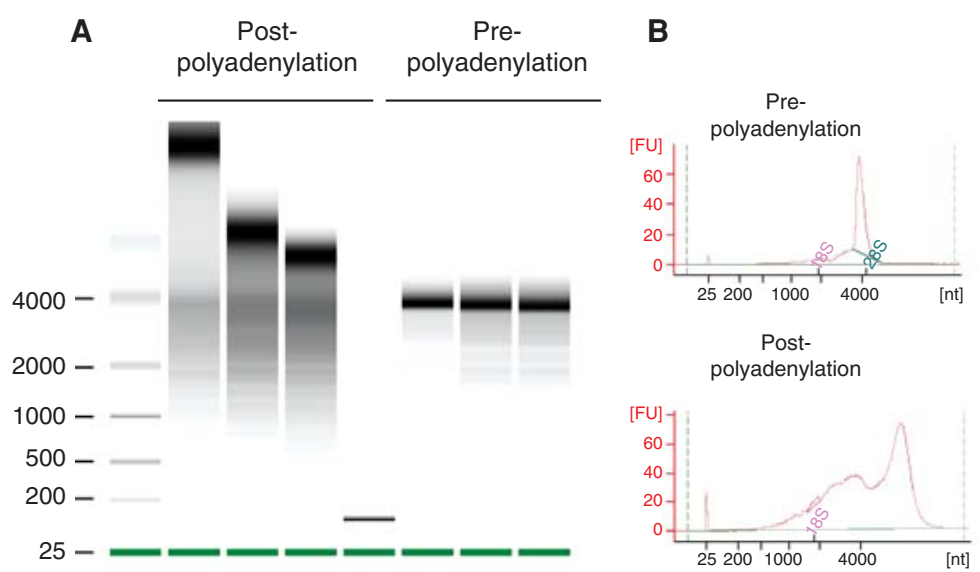

\section{C}

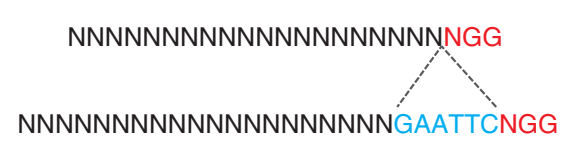

FIGURE 1. Quality control of Cas9 mRNA in a 2100 Bioanalyzer and ssDNA donor oligo design. (A) Electrophoresis of in vitro-transcribed Cas9 mRNA pre- and postpolyadenylation. (B) Electropherogram of in vitro-transcribed Cas9 mRNA pre- and postpolyadenylation. $(C)$ Representation of a sequence that can be targeted with a specific sgRNA. Insertion of EcoRI (as an example; blue) adjacent to the PAM sequence (red) will preclude the Cas9 endonuclease from cutting again after the genome has been repaired by HDR. 
J. Henao-Mejia et al.

9. After purification, determine the quality of the Cas9 mRNA by analyzing $2.5 \mu \mathrm{L}$ of the Cas 9 mRNA pre- and postpolyadenylation in a Bioanalyzer using the Agilent RNA 6000 Pico reagents and chips according to the manufacturer's instructions.

A discrete $\sim 4-k b$ band should be observable in the sample prepolyadenylation, with an upward shift postpolyadenylation (Fig. 1A). Smeared bands indicate degradation. Discard degraded samples.

10. Calculate the concentration of the Cas9 mRNA according to the values reported in the Bioanalyzer (Fig. 1B).

11. Dilute the Cas 9 mRNA to $400 \mathrm{ng} / \mu \mathrm{L}$ in nuclease-free microinjection buffer ( $5 \mathrm{~mm}$ Tris- $\mathrm{HCl}, \mathrm{pH}$ 7.4, $0.1 \mathrm{~mm}$ EDTA, $\mathrm{pH}$ 8.0). Freeze aliquots at $-80^{\circ} \mathrm{C}$.

In Vitro Transcription and Purification of sgRNAs

12. For sgRNA preparation, add the T7 promoter sequence to the sgRNA template(s) (from Step 1, as appropriate) by PCR amplification using the T7-sgRNA_F and sgRNA_R primers as follows.

\begin{tabular}{lrl} 
Reagent & Volume & Final conc. \\
\hline sgRNA template $(300 \mathrm{ng} / \mu \mathrm{L})$ & $4 \mu \mathrm{L}$ & $1200 \mathrm{ng}$ \\
High-fidelity buffer $(10 \times)$ & $40 \mu \mathrm{L}$ & $1 \times$ \\
MgSO $_{4}(50 \mathrm{~mm})$ & $12 \mu \mathrm{L}$ & $1.5 \mathrm{~mm}$ \\
dNTPs $(10 \mathrm{~mm})$ & $8 \mu \mathrm{L}$ & $0.2 \mathrm{~mm}$ \\
T7-sgRNA_F $(10 \mu \mathrm{M})$ & $8 \mu \mathrm{L}$ & $0.2 \mu \mathrm{M}$ \\
sgRNA_R $(10 \mu \mathrm{M})$ & $8 \mu \mathrm{L}$ & $0.2 \mu \mathrm{M}$ \\
High-fidelity polymerase & $2.4 \mu \mathrm{L}$ & \\
Nuclease-free water & $317.6 \mu \mathrm{L}$ &
\end{tabular}

13. Divide this PCR into eight PCR tubes ( $50 \mu \mathrm{L} / \mathrm{each})$ and perform amplification using the following cycling conditions.

\begin{tabular}{llll} 
Cycle number & Denaturation & Annealing & Elongation \\
\hline 1 & $94^{\circ} \mathrm{C}, 2 \mathrm{~min}$ & & \\
$2-35$ & $94^{\circ} \mathrm{C}, 20 \mathrm{sec}$ & $55^{\circ} \mathrm{C}, 30 \mathrm{sec}$ & $68^{\circ} \mathrm{C}, 40 \mathrm{sec}$ \\
36 & & & $68^{\circ} \mathrm{C}, 7 \mathrm{~min}$
\end{tabular}

14. Analyze $5 \mu \mathrm{L}$ of the PCR on a $2.5 \%(\mathrm{w} / \mathrm{v})$ agarose gel in $1 \times$ TAE buffer to verify that the product is unique and of the expected size.

The size of the PCR product is $\sim 120$ bp for sgRNA templates.

15. Purify the T7-sgRNA PCR product using the QIAquick PCR purification kit according to the manufacturer's instructions.

16. Elute in $30 \mu \mathrm{L}$ of nuclease-free water and resuspend the purified PCR product to a concentration of $120.5 \mathrm{ng} / \mu \mathrm{L}$.

17. Use $1 \mu \mathrm{L}$ of the purified T7-sgRNA PCR product as the template for in vitro transcription of sgRNA using the MEGAshortscript T7 Transcription Kit according to the manufacturer's instructions.

18. Purify the sgRNA using the MEGAclear Transcription Clean-Up Kit and elute with elution buffer according to the manufacturer's instructions.

19. Dilute the sgRNA to $500 \mathrm{ng} / \mu \mathrm{L}$ in nuclease-free microinjection buffer ( $5 \mathrm{~mm}$ Tris- $\mathrm{HCl}, \mathrm{pH} 7.4$, 0.1 mM EDTA, pH 8.0).

20. Verify the sgRNA's quality on a $2 \%(\mathrm{w} / \mathrm{v})$ agarose gel in TAE buffer.

Smeared bands indicate degradation. Discard degraded samples.

21. Freeze $30-40 \mu \mathrm{L}$ aliquots at $-80^{\circ} \mathrm{C}$. 


\section{Purification of Donor DNA}

\section{For ssDNA Used to Insert Small DNA Fragments}

22. Purify the donor ssDNA (from Step 2, as appropriate) using the ssDNA/RNA clean and concentrator kit according to the manufacturer's instructions and elute with $100 \mu \mathrm{L}$ of elution buffer.

23. Dilute the donor ssDNA to $500 \mathrm{ng} / \mu \mathrm{L}$ in nuclease-free microinjection buffer ( $5 \mathrm{~mm}$ Tris- $\mathrm{HCl}, \mathrm{pH}$ 7.4, 0.1 mM EDTA, pH 8.0).

24. Freeze $30-40 \mu \mathrm{L}$ aliquots at $-80^{\circ} \mathrm{C}$.

\section{For Circular DNA Used to Insert Large DNA Fragments}

25. Prepare the circular DNA donor vector (from Step 2) using the EndoFree plasmid maxi kit according to the manufacturer's instructions.

26. Purify the circular DNA donor vector using the QIAquick PCR purification kit according to the manufacturer's instructions. Elute in $30 \mu \mathrm{L}$ of nuclease-free microinjection buffer ( $5 \mathrm{~mm}$ Tris$\mathrm{HCl}, \mathrm{pH} 7.4,0.1 \mathrm{~mm}$ EDTA, $\mathrm{pH} 8.0)$. Freeze aliquots at $-80^{\circ} \mathrm{C}$.

\section{Preparation of Samples for Microinjection}

27. Centrifuge thawed stock aliquots of the Cas9 mRNA (from Step 11), sgRNAs (from Step 21), and/or ssDNA donor oligos (from Step 24) at 13,200 rpm for $10 \mathrm{~min}$ at $4^{\circ} \mathrm{C}$.

28. Depending on the aim of the experiment, prepare the appropriate injection mix by combining the components in an RNase-free microcentrifuge tube as described below.

- For gene disruption by nonhomologous end joining or small/large chromosomal deletions add $10 \mu \mathrm{L}$ of Cas9 mRNA stock (from Step 11), $4 \mu \mathrm{L}$ of each sgRNA stock (from Step 21), and nuclease-free microinjection buffer up to $40 \mu \mathrm{L}$.

The final concentrations are $100 \mathrm{ng} / \mu \mathrm{L}$ of Cas9 mRNA and 50-100 $\mathrm{ng} / \mu \mathrm{L}$ of each $s g R N A$.

- For point mutations, small tag insertions or conditional allele generation by HDR add $10 \mu \mathrm{L}$ of Cas9 mRNA stock (from Step 11), $4 \mu \mathrm{L}$ of each sgRNA stock (from Step 21), $8 \mu \mathrm{L}$ of donor ssDNA stock (from Step 24), and nuclease-free microinjection buffer up to $40 \mu \mathrm{L}$.

The final concentrations are $100 \mathrm{ng} / \mu \mathrm{L}$ of Cas9 mRNA, 50-100 ng/ $\mathrm{L}$ of each $\mathrm{sgRNA}$, and $100 \mathrm{ng} / \mu \mathrm{L}$ of each donor ssDNA.

- For large fragment insertion by HR add $10 \mu \mathrm{L}$ of Cas9 mRNA stock (from Step 11), $4 \mu \mathrm{L}$ of each sgRNA stock (from Step 21), the circular DNA donor vector (from Step 26), and nuclease-free microinjection buffer up to $40 \mu \mathrm{L}$.

The final concentrations are $100 \mathrm{ng} / \mu \mathrm{L}$ of Cas $9 \mathrm{mRNA}, 50-100 \mathrm{ng} / \mu \mathrm{L}$ of each $\mathrm{sgRNA}$, and $200 \mathrm{ng} / \mu \mathrm{L}$ of the circular DNA donor vector.

29. Centrifuge the microinjection mixture at $13,200 \mathrm{rpm}$ for $6 \mathrm{~min}$ at $4^{\circ} \mathrm{C}$. Remove $30 \mu \mathrm{L}$ and transfer to a new RNase-free microcentrifuge tube.

30. Centrifuge the microinjection mixture at $13,200 \mathrm{rpm}$ for $6 \mathrm{~min}$ at $4^{\circ} \mathrm{C}$. Place the mixture on ice and begin microinjection.

\section{Zygote Preparation}

31. Inject 15 female C57BL/6-(3- to 4-wk-old) mice with PMSG (5 IU) on day 1.

32. After $48 \mathrm{~h}$ (i.e., on day 3), inject female mice with hCG (5 IU). After the hCG injection, house female mice with C57BL/6 male mice of proven fertility overnight.

33. On the morning of day 4 , collect female mice with cervical plugs for zygote preparation. Euthanize the female mice without plugs. 
34. Prepare the medium for embryo culture.

i. Place several drops (30-50 $\mu \mathrm{L}$ per drop) of M16 medium on a 60-mm dish.

ii. Cover the drops with light mineral oil.

iii. Place the dish into a $37^{\circ} \mathrm{C}$ incubator for at least $30 \mathrm{~min}$ before use.

35. At $20-21 \mathrm{~h}$ after hCG injection, kill the mice and collect zygote-cumulus complexes from the oviduct.

36. Prepare the medium for embryo collection by adding hyaluronidase to M2 media to obtain a working concentration of $300 \mu \mathrm{g} / \mathrm{mL}$ (M2 + Hy medium).

37. Move the zygote-cumulus complexes into M2 + Hy medium in a 100-mm dish. Pipette up and down several times. Aspirate the embryos with a transfer pipette.

38. Wash several times in M2 medium.

39. Place the embryos into $\mathrm{M} 16$ medium at $37^{\circ} \mathrm{C}$ in a $5 \% \mathrm{CO}_{2}$ incubator until ready for microinjection.

\section{Microinjection of Zygotes}

40. Use a transfer pipette to transfer a group of fertilized oocytes into the injection chamber containing M16 medium. Wait for at least 5 min before starting the injection.

The number of zygotes to be moved into the microinjection drop should be determined by the skills of the injector and quality of the setup.

41. Examine the zygotes under high power, making sure that two pronuclei are visible and that the morphology is good. Discard all zygotes that appear abnormal.

42. Aspirate the injection mix into microinjection capillary.

43. Determine whether the microinjection capillary is open and unclogged by placing the tip of the microinjection capillary close to a zygote in the same horizontal plane under a continuous flow stream.

If the microinjection capillary is open, a stream of DNA will move the zygote away from the tip of the microinjection capillary. See Troubleshooting.

44. To prepare a zygote for injection, place the tip of the holding pipette next to the zygote, and apply a negative pressure to the pressure control unit.

45. Focus the microscope to locate the pronuclei.

The pronucleus should also be as close as possible to the central axis of the holding pipette.

46. Refocus on the pronucleus to be injected. Bring the tip of the microinjection capillary into the same focal plane as the mid-plane of the pronucleus.

47. Move the injection pipette to the same $y$-axis position as the targeted pronucleus.

48. Adjust the height of the pipette so that the tip of the microinjection capillary appears completely sharp.

49. Move the injection pipette to a 3 o'clock position without changing its height.

50. Push the microinjection pipette through the zona pellucida into the cytoplasm and toward the pronucleus.

51. When the tip of the microinjection capillary appears to be inside the cytoplasm apply injection pressure through the injector.

If the cytoplasm swells visibly, it has been successfully injected. If the cytoplasm does not swell, the pipette has become clogged or has not punctured the oocyte plasma membrane. If a small round "bubble" forms around the tip of the pipette, then the pipette has not punctured the plasma membrane. Cytoplasmic granules flowing out of the oocyte after removal of the injection pipette are a clear sign that the zygote will soon lyse. In this case, the oocyte should be discarded. If the zygote appears to be intact and successfully injected, it should be sorted and another zygote should be picked up for injection. 
52. Quickly pull the pipette out of the zygote.

53. Repeat Steps 44-52 with the remaining zygotes.

Some injected zygotes will inevitably lyse because of the mechanical damage caused by the injection procedure. The lysed zygotes can be distinguished from healthy ones by the appearance of the zona pellucida as it is more translucid. Typically, $75 \%$ of the zygotes survive the microinjection.

54. After all the zygotes in the chamber have been injected immediately transfer them back into M16 medium and incubate at $37^{\circ} \mathrm{C}$ in a $5 \% \mathrm{CO}_{2}$ incubator.

\section{Embryo Transfer and Production of Mice}

55. Prepare pseudopregnant foster mothers by mating estrous CD1 female mice with vasectomized male mice on the same day as injection.

56. Transfer approximately 25 microinjected zygotes into oviducts of $0.5 \mathrm{~d}$ postcoitum (dpc) recipients.

Alternatively, injected zygotes can be cultured in $\mathrm{M} 16$ medium at $37^{\circ} \mathrm{C}$ in a $5 \% \mathrm{CO}_{2}$ incubator until they reach the two-cell stage $24 \mathrm{~h}$ later and then be transferred into oviducts of $0.5 \mathrm{~d}$ postcoitum (dpc) recipients.

57. Deliver pups from recipient mothers at $19.5 \mathrm{dpc}$.

58. Separate male and female offspring into individual cages at $3 \mathrm{wk}$ after birth.

\section{Genotyping}

59. Extract genomic DNA from tail biopsies of 10-d-old mice using a DNeasy blood and tissue kit according to the manufacturer's protocol.

\section{For Small Genomic Modifications}

60. To genotype small genomic modifications such as point mutations, gene disruptions, small sequence insertions, or conditional alleles, perform PCR amplification using gene-specific primers under the following conditions.

\begin{tabular}{|c|c|c|c|}
\hline Reagent & & Volume & Final concentration \\
\hline Genomic DNA & & $2.5 \mu \mathrm{L}$ & \\
\hline Tsg buffer $(10 \times)$ & & $2.5 \mu \mathrm{L}$ & $1 \times$ \\
\hline $\mathrm{MgCl}_{2}$ & & $1.5 \mu \mathrm{L}$ & $1.5 \mathrm{~mm}$ \\
\hline dNTPs (10 mm) & & $0.5 \mu \mathrm{L}$ & $0.2 \mathrm{~mm}$ \\
\hline Primer_F $(10 \mu \mathrm{M})$ & & $0.5 \mu \mathrm{L}$ & $0.2 \mu \mathrm{M}$ \\
\hline Primer_R $(10 \mu \mathrm{M})$ & & $0.5 \mu \mathrm{L}$ & $0.2 \mu \mathrm{M}$ \\
\hline Tsg polymerase & & $0.3 \mu \mathrm{L}$ & \\
\hline Nuclease-free water & & $16.7 \mu \mathrm{L}$ & \\
\hline Cycle number & Denaturation & Annealing & Elongation \\
\hline 1 & $95^{\circ} \mathrm{C}, 2 \mathrm{~min}$ & & \\
\hline $2-35$ & $94^{\circ} \mathrm{C}, 30 \mathrm{sec}$ & $\begin{array}{l}72^{\circ} \mathrm{C}, 30 \mathrm{sec}, \\
\quad-0.5^{\circ} \mathrm{C} / \text { cycle }\end{array}$ & $72^{\circ} \mathrm{C}, 45 \mathrm{sec}$ \\
\hline 36 & & & $72^{\circ} \mathrm{C}, 7 \mathrm{~min}$ \\
\hline
\end{tabular}

61. If desired, purify the PCR products by using the QIAquick PCR Purification Kit according to the manufacturer's instructions. Then analyze the PCR products by one of the following methods.

- To check for indels or small mutations perform a SURVEYOR assay according to the manufacturer's instructions.

This can be performed directly on the (unpurified) PCR product. 
J. Henao-Mejia et al.

- If a restriction enzyme recognition site has been inserted or removed, perform restriction enzyme digestion of the PCR product.

- To verify mutations, clone the PCR products using the TOPO TA Cloning kit and sequence according to the manufacturer's instructions.

\section{For Insertions of Tags, loxPs, or Deletions}

62. To genotype for insertions of tags, loxPs or deletions, perform PCR amplification using genespecific primers under the following conditions.

\begin{tabular}{|c|c|c|c|}
\hline Reagent & Volume & \multicolumn{2}{|c|}{ Final concentration } \\
\hline Genomic DNA & $2.5 \mu \mathrm{L}$ & & \\
\hline Tsg buffer $(10 \times)$ & $2.5 \mu \mathrm{L}$ & $1 \times$ & \\
\hline $\mathrm{MgCl}_{2}$ & $1.5 \mu \mathrm{L}$ & $1.5 \mathrm{~mm}$ & \\
\hline dNTPs (10 mм) & $0.5 \mu \mathrm{L}$ & $0.2 \mathrm{~mm}$ & \\
\hline Primer_F $(10 \mu \mathrm{M})$ & $0.5 \mu \mathrm{L}$ & $0.2 \mu \mathrm{M}$ & \\
\hline Primer_R $(10 \mu \mathrm{M})$ & $0.5 \mu \mathrm{L}$ & $0.2 \mu \mathrm{M}$ & \\
\hline Tsg polymerase & $0.3 \mu \mathrm{L}$ & & \\
\hline Nuclease-free water & $16.7 \mu \mathrm{L}$ & & \\
\hline Cycle number & Denaturation & Annealing & Elongation \\
\hline 1 & $95^{\circ} \mathrm{C}, 2 \mathrm{~min}$ & & \\
\hline $2-35$ & $94^{\circ} \mathrm{C}, 30 \mathrm{sec}$ & $\begin{array}{c}72^{\circ} \mathrm{C}, 30 \mathrm{sec} \\
-0.5^{\circ} \mathrm{C} / \mathrm{cycle}\end{array}$ & $72^{\circ} \mathrm{C}, 45 \mathrm{sec}$ \\
\hline 36 & & & $72^{\circ} \mathrm{C}, 7 \mathrm{~min}$ \\
\hline
\end{tabular}

63. Analyze the PCR product on a $2 \%(w / v)$ agarose gel in $1 \mathrm{X}$ TAE buffer to verify that the product is unique and of the expected size.

\section{For Large Insertions}

64. To genotype for large insertions perform PCR amplification for large fragments using genespecific primers that allows detecting the insertion of the fragment at the specific genomic location.

PCR conditions should be optimized in each case.

Problem (Step 43): The microinjection pipette is closed or clogged.

Solution: Flush DNA with high power through the microinjection capillary by using the "Clear" function on the microinjector. Repeat the test. If the tip is still not open, tip it carefully on the holding pipette to break the tip to a larger diameter. If the diameter becomes too large, or the tip is still not open, discard the pipette and use a new one.

\section{DISCUSSION}

Based on the targeting experiments we have performed (more than 400 different microinjections producing more than 100 new mouse strains), the great majority of microinjections with only Cas9 mRNA and sgRNAs resulted in mutant alleles containing indels with high efficiency $(>80 \%$ of pups were targeted for one allele). The efficiency of targeted chromosomal deletions greatly depends on the size of the deletion; we have successfully deleted chromosomal regions up to $\sim 200 \mathrm{~kb}$ and have observed efficiencies for targeted deletions that range from $10 \%$ to $40 \%$ of born pups being targeted. With co-injection of donor ssDNA, the efficiency of HDR varies from $10 \%$ to $60 \%$ depending on the 
size of the fragment that is being inserted/modified. Using double-stranded plasmid donor DNA, the efficiency of HR varies greatly and requires significant optimization.

\section{RELATED INFORMATION}

A more detailed discussion on the background and uses of these techniques is available in Introduction: Editing the Mouse Genome Using the CRISPR-Cas9 System (Williams et al. 2016).

\section{RECIPES}

\section{$S D S$}

Also called sodium dodecyl sulfate or sodium lauryl sulfate. To prepare a $20 \%(\mathrm{w} / \mathrm{v})$ solution, dissolve $200 \mathrm{~g}$ of electrophoresis-grade SDS in $900 \mathrm{~mL}$ of $\mathrm{H}_{2} \mathrm{O}$. Heat to $68^{\circ} \mathrm{C}$ and stir with a magnetic stirrer to assist dissolution. If necessary, adjust the $\mathrm{pH}$ to 7.2 by adding a few drops of concentrated $\mathrm{HCl}$. Adjust the volume to $1 \mathrm{~L}$ with $\mathrm{H}_{2} \mathrm{O}$. Store at room temperature. Sterilization is not necessary. Do not autoclave.

$T A E$

Prepare a $50 \times$ stock solution in $1 \mathrm{~L}$ of $\mathrm{H}_{2} \mathrm{O}$ :

$242 \mathrm{~g}$ of Tris base

$57.1 \mathrm{~mL}$ of acetic acid (glacial)

$100 \mathrm{~mL}$ of 0.5 м EDTA (pH 8.0)

The $1 \times$ working solution is $40 \mathrm{~mm}$ Tris-acetate/ $1 \mathrm{~mm}$ EDTA.

\section{REFERENCES}

Ran FA, Hsu PD, Wright J, Agarwala V, Scott DA, Zhang F. 2013. Genome engineering using the CRISPR-Cas9 system. Nat Protoc 8: 2281-2308.
Williams A, Henao-Mejia J, Flavell R. 2016. Editing the mouse genome using the CRISPR-Cas9 system. Cold Spring Harb Protoc doi: 10.1101/pdb. top087536. 


\section{Generation of Genetically Modified Mice Using the CRISPR-Cas9 Genome-Editing System}

Jorge Henao-Mejia, Adam Williams, Anthony Rongvaux, Judith Stein, Cynthia Hughes and Richard A. Flavell

Cold Spring Harb Protoc; doi: 10.1101/pdb.prot090704

\begin{tabular}{rc}
$\begin{array}{r}\text { Email Alerting } \\
\text { Service }\end{array}$ & Receive free email alerts when new articles cite this article - click here. \\
\hline $\begin{array}{c}\text { Subject } \\
\text { Categories }\end{array}$ & Browse articles on similar topics from Cold Spring Harbor Protocols. \\
& Molecular Biology, general (1293 articles) \\
& Mouse (437 articles) \\
& Mutagenesis (57 articles) \\
& RNA (317 articles) \\
& RNA, general (269 articles) \\
& Transgenic Mice (139 articles) \\
\hline
\end{tabular}

